\title{
Cardiac conduction abnormalities and rhythm changes after neonatal anatomical correction of transposition of the great arteries
}

\author{
S Menahem, M S Ranjit, C Stewart, W J Brawn, R B B Mee, J L Wilkinson
}

\begin{abstract}
Seventy three infants who underwent neonatal anatomical correction for transposition of the great arteries with or without a ventricular septal defect were reviewed for evidence of conduction and rhythm abnormalities on preoperative and postoperative 12 lead electrocardiograms and during 24 hour Holter monitoring. There was a partial right bundle branch block pattern in $47 \%(29 / 62)$ of all patients and in $60 \%$ (24/40) of those with simple transposition. Complete right bundle branch block was noted in $21 \%$ including $5 \%$ with simple transposition. Holter monitoring showed sinus rhythm in all patients except three: one had episodes of supraventricular tachycardia, another an intermittent second degree heart block, and a third a complete heart block. Atrial extrasystoles were noted in $47 \%(29 / 62)$ of patients but were frequent in only three patients. Occasional unifocal ventricular extrasystoles were encountered in $37 \%(23 / 62)$ of patients and were frequent in a further $3 \%(2 / 62)$. Only one patient $(2 \%)$ developed multifocal ventricular extrasystoles. The frequency of important cardiac arrhythmias after neonatal anatomical correction of transposition of the great arteries was $5 \%$, significantly less than that reported after atrial inflow diversion for the same malformation.
\end{abstract}

In the past decade anatomical correction has become the treatment of choice for simple transposition of the great arteries as well as for transposition with ventricular septal defect. Early concerns ${ }^{1-3}$ included the ideal age for surgery, late ventricular function, neo-aortic valve competence, late coronary ostial stenosis, growth of the atrial anastomoses and the frequency of postoperative arrhythmias. ${ }^{45}$ Many of these concerns have been allayed to a large extent, ${ }^{6-8}$ though reports of pulmonary artery stenosis are not uncommon. ${ }^{8-10}$ Normal ventricular function has been reported, ${ }^{10-13}$ together with a low frequency of important arrhythmias in the postoperative period. ${ }^{14-16}$

These earlier studies of rhythm disturbances included a heterogenous group where the anatomical correction was done usually later in infancy after earlier banding of the pulmonary artery. ${ }^{14} 15$ In a subsequent study
54 of the 92 patients reviewed had a primary (1 stage) anatomical correction, but 23 of the 29 who had their ventricular septal defect closed required a ventriculotomy. ${ }^{16}$ Neonatal arterial switches including closure of a ventricular septal defect without the need for a ventriculotomy have been successfully performed at this centre since $1983 .^{7}$ Such patients formed a homogeneous group subjected to early correction and in whom conduction and rhythm disturbances could be studied before (whenever such information was available) and after operation.

\section{Patients and methods}

We studied all patients who had transposition of the great vessels or transposition with a ventricular septal defect and who had correction in the neonatal period and were subsequently followed up at our hospital. The former group also included infants with a small ventricular septal defect that did not require closure. We excluded patients with "complex" transposition-for example double outlet right ventricle or those with multiple ventricular septal defects. We also excluded the few infants who had surgery beyond the neonatal period or those who had an initial pulmonary artery banding done before anatomical correction. None of the patients had a ventriculotomy for closure of a ventricular septal defect. We also excluded patients returning overseas, or leaving the state, or lost to follow up.

The records of each infant were reviewed and any preoperative or postoperative risk factors that might predispose to an arrhythmia were noted. Special attention was given to the coronary artery patterns as well as any difficulties encountered in their transfer. At follow up (mean duration 27 months and up to 68 months) the clinical, cross sectional echocardiographic, and cardiac catheterisation findings were noted. All available preoperative (before and after balloon atrial septostomy), postoperative, and serial follow up electrocardiograms were reviewed. After the study started a sample group of patients underwent 24 hour Holter monitoring preoperatively and in the immediate postoperative period for the purpose of comparison. Subsequent 24 hour Holter recordings were obtained after admission for postoperative cardiac catheterisation, at review appointments, or after letters of recall. All such Holter monitoring was carried 
Table 1 Clinical details

\begin{tabular}{llll}
\hline & \multicolumn{2}{l}{ Anatomy } & \\
\cline { 2 - 4 } Data & Simple TGA & TGA with VSD & Total \\
\hline Patients & 49 & 24 & 73 \\
Age at switch (days): & $3-28$ & $8-28$ & $3-28$ \\
$\quad$ Range & 12 & 15 & $2-68$ \\
$\quad$ Mean & $2-63$ & 3 & $2-68$ \\
Follow up (mnth) (range) & 13 & 4 & 16 \\
Holter recordings: & 13 & 23 & 17 \\
$\quad$ Preoperative (n) & 37 & $2-68(29)$ & 60 \\
$\quad$ Postoperative (n) & $5-60(26)$ & & $2-68(27)$ \\
Follow up & Range (mean) (mnth) & &
\end{tabular}

TGA, transposition of the great arteries; VSD, ventricular septal defect.

out when the subject was off medical treatment except for one who was taking digoxin for supraventricular tachycardia. All the electrocardiograms were examined for any conduction abnormalities or arrhythmia. The Texas Children's Hospital Pediatric Electrocardiographic norms were used in interpretation, ${ }^{17}$ and all abnormal findings were tabulated. The Holter recordings were reported by an experienced cardiac technician (CS) and hard copies of any arrhythmias were reviewed by the cardiologist. Like Martin et al $^{16}$ short periods of sinus bradycardia (over $50 /$ minute) or of sinus tachycardia (under 180/ minute) were accepted as being within normal limits, as was sinus arrhythmia or brief sinus pauses. ${ }^{18-23}$ Right bundle branch block was diagnosed when a typical rsR pattern was seen in V1 and V2 associated with broad S waves in V6 and when the QRS duration was above the upper limit for age. A similar pattern with a normal QRS interval was diagnosed as partial right bundle branch block. Less than 12 supraventricular extrasystoles per peak hour were classified as being occasional and more than 12 per peak hour as frequent. Supraventricular tachycardia was diagnosed when it occurred for more than three beats in succession. Ventricular arrhythmias were classified according to the modified Lown criteria. ${ }^{16}$

\section{Results}

Seventy three patients who had a neonatal arterial switch operation and who satisfied the above selection criteria were included in the study group. Forty nine had simple transposition and 24 had transposition with ventricular septal defect requiring closure. All patients had a balloon atrial septostomy at presentation. Table 1 summarises their clinical details. Fifty three per cent ( 39 neonates) had surgery in the first two weeks of life. There was difficulty in transferring the coronary arteries in four patients. In two the infundibular branch had to be sacrificed, while the other two needed stay sutures or reimplantation of the coronary artery because of kinking of the right coronary artery.

Tables 2 and 3 summarise the details of the electrocardiograms and Holter traces: not all the infants had preoperative electrocardiograms. Preoperative and immediate postoperative (first two weeks) 24 hour Holter recordings were available from 16 and 17 patients respectively.

\section{ELECTROCARDIOGRAPHIC FINDINGS}

Two patients had transient evidence of myocardial ischaemia in the postoperative period. Thirteen others $(18 \%)$ had non-specific ST segment or T wave changes in the electrocardiogram recorded immediately after operation. ${ }^{15}$ At follow up none of the patients had persistent evidence of ischaemia or any ST segment or $\mathrm{T}$ wave changes. Ischaemic changes did not develop in any of the patients in whom there was difficulty in transfer of the coronary arteries.

Partial right bundle branch block, seen in $7 \%$ of patients preoperatively (five out of 64 who had a preoperative electrocardiogram) and at follow up in $47 \%(29 / 62)$, was the commonest "conduction" abnormality noted. Complete right bundle branch block was not seen preoperatively but was found in $21 \%(13 / 62)$ postoperatively. Two patients with simple transposition who developed right bundle branch block postoperatively had only a partial right bundle branch block at later follow up. Two others with simple transposition who in the immediate postoperative period had only a partial right bundle branch block went on to develop a complete right bundle branch block. All other patients with complete right bundle branch block had a ventricular septal defect closed. A partial right bundle branch block pattern disappeared in three patients. Right bundle branch block with left axis deviation was seen in $5 \%(3 / 62)$ of patients at follow up.

First degree heart block was seen in $5 \%$ (3/62) of patients, while one patient displayed intermittent second degree Wenckebach atrioventricular block on late follow up.

Table 2 Preoperative and postoperative electrocardiographic abnormalities

\begin{tabular}{|c|c|c|c|c|c|c|c|c|c|}
\hline \multirow[b]{2}{*}{ Patients } & \multicolumn{4}{|c|}{ Simple transposition $(n)(\%)$} & \multicolumn{4}{|c|}{ Transposition with VSD (n) (\%) } & \multirow{2}{*}{$\begin{array}{l}\text { All cases } \\
\begin{array}{l}\text { Follow up (n) (\%) } \\
(62 / 73)\end{array}\end{array}$} \\
\hline & $\begin{array}{l}\text { Pre BAS } \\
(43 / 49)\end{array}$ & $\begin{array}{l}\text { Post BAS } \\
(45 / 49)\end{array}$ & $\begin{array}{l}\text { Post op } \\
(49 / 49)\end{array}$ & $\begin{array}{l}\text { Follow up } \\
(40 / 49)\end{array}$ & $\begin{array}{l}\text { Pre BAS } \\
(21 / 24)\end{array}$ & $\begin{array}{l}\text { Post BAS } \\
(21 / 24)\end{array}$ & $\begin{array}{l}\text { Post op } \\
(23 / 24)\end{array}$ & $\begin{array}{l}\text { Follow up } \\
(22 / 24)\end{array}$ & \\
\hline $\begin{array}{l}\text { Partial RBBB } \\
\text { Complete BBB } \\
\text { Left axis deviation } \\
\text { LAD }+ \text { RBBB } \\
\text { I }^{\circ} \text { heart block } \\
\text { II }^{\circ} \text { heart block } \\
\text { Complete heart block } \\
\text { Non-specific ST/T wave changes } \\
\text { Ischaemia }\end{array}$ & $\begin{array}{l}4(9) \\
0 \\
1(2) \\
0 \\
0 \\
0 \\
0 \\
\text { es2 } \\
0 \\
0\end{array}$ & $\begin{array}{l}4(9) \\
0 \\
1(2) \\
0 \\
0 \\
0 \\
0 \\
1 \\
0\end{array}$ & $\begin{array}{rr}34 & (69) \\
2 & (4) \\
2 & (4) \\
0 & \\
0 \\
0 \\
0 \\
9 \\
0 \\
0\end{array}$ & $\begin{array}{rr}24 & (60) \\
2 & (5) \\
1 & (3) \\
0 & \\
3 & (13) \\
0 & \\
0 \\
0 \\
0\end{array}$ & $\begin{array}{l}1(5) \\
0 \\
2(9) \\
0 \\
0 \\
0 \\
0 \\
1(5) \\
0\end{array}$ & $\begin{array}{l}0 \\
0 \\
3 \\
0 \\
0 \\
0 \\
0 \\
0 \\
1 \\
0\end{array}$ & $\begin{array}{rr}6 & (25) \\
11 & (48) \\
1 & (4) \\
3 & (13) \\
0 & \\
0 & \\
1 & (4) \\
4 & (17) \\
2 & (8)\end{array}$ & $\begin{array}{rr}5 & (23) \\
11 & (50) \\
1 & (5) \\
3 & (14) \\
0 & \\
1 & (4) \\
1 & (4) \\
0 & \\
0 & \end{array}$ & $\begin{array}{rr}29 & (47) \\
13 & (21) \\
2 & (3) \\
3 & (5) \\
3 & (5) \\
1 & (2) \\
1 & (2) \\
0 & \\
0 & \end{array}$ \\
\hline
\end{tabular}

RBBB, right bundle branch block; LAD, left axis deviation; ST/T wave changes, ST segment or T wave changes; BAS, balloon atrial septostomy; $I^{\circ}$, first degree

II $^{\circ}$, second degree. 
Table 324 hour Holter monitoring : preoperative and postoperative arrhythmias

\begin{tabular}{|c|c|c|c|c|c|c|c|}
\hline & \multicolumn{3}{|c|}{ Simple transposition $(n)(\%)$} & \multicolumn{3}{|c|}{ Transposition with VSD (n) (\%) } & \multirow{2}{*}{$\begin{array}{l}\text { All cases at } \\
\text { follow up (n) }(\%) \\
62\end{array}$} \\
\hline & $\begin{array}{l}\text { Pre op } \\
13\end{array}$ & $\begin{array}{l}\text { Post op } \\
13\end{array}$ & $\begin{array}{l}\text { Follow up } \\
39\end{array}$ & $\begin{array}{l}\text { Pre op } \\
3\end{array}$ & $\begin{array}{l}\text { Post op } \\
4\end{array}$ & $\begin{array}{l}\text { Follow up } \\
25\end{array}$ & \\
\hline \multirow{3}{*}{$\begin{array}{l}\text { SVE (occasional) } \\
\text { SVE (frequent) } \\
\text { Sinus slowing with }\end{array}$} & $1 \quad(8)$ & $9(69)$ & $17(43)$ & $1(33)$ & $3(75)$ & $9(38)$ & $26(42)$ \\
\hline & $1(8)$ & & $3(8)$ & 0 & 0 & & 3 (5) \\
\hline & & & & & & & \\
\hline SVE/JE & $3(23)$ & $1(8)$ & $5(13)$ & 0 & 0 & $2(8)$ & $7(11)$ \\
\hline SVT & 18 & $18)$ & 1 (3) & 0 & 0 & & 1 (2) \\
\hline Junctional tachycardia & 0 & 1 (8) & 0 & 0 & 0 & 0 & 0 \\
\hline \multicolumn{8}{|l|}{ Ventricular arrhythmia: } \\
\hline Grade I & & $5(38)$ & $14(36)$ & $2(66)$ & $1(25)$ & $9(38)$ & $23(37)$ \\
\hline Grade II & $1(8)$ & $2(16)$ & 2 (5) & & & & 2 (3) \\
\hline Grade III & $1(8)$ & 1 (8) & 1 (3) & 0 & $1(25)$ & 0 & 1 (2) \\
\hline Grade IV & 0 & 0 & 0 & 0 & 0 & $\mathbf{0}$ & 0 \\
\hline Grade V & 0 & $1(8)$ & 0 & 0 & 0 & 0 & 0 \\
\hline
\end{tabular}

SVE, supraventricular extrasystoles; occasional, less than 12 beats in a peak hour; frequent, over 12 per peak hour; SVT, supraventricular tachycardia; JE, junctional extrasystoles.

Another infant with transposition and ventricular septal defect developed complete heart block after surgical correction.

\section{HOLTER MONITORING}

Preoperatively one neonate had supraventricular tachycardia, soon after balloon atrial septostomy. Follow up electrocardiograms and Holter recordings from this symptom free child showed sinus rhythm. A further patient with supraventricular tachycardia in the immediate postoperative period also had sinus rhythm on follow up two years after surgery. In another patient symptomatic supraventricular tachycardia at follow up $(1 / 62,2 \%)$ was controlled by digoxin; subsequent Holter recording two years after surgery showed sinus rhythm. Apart from the patient who developed postoperative complete heart block and another with intermittent Wenckebach block all others remained in sinus rhythm. However, seven $(11 \%)$ patients at follow up showed brief sinus pauses with atrial or junctional escape beats. Two others had $\mathbf{P}$ waves with two different configurations on Holter recordings.

Isolated supraventricular extrasystoles were seen in $42 \%(26 / 62)$ of patients (rate of less than 12 beats per peak hour) on follow up. In a further $5 \%(3 / 62)$ of patients more frequent supraventricular extrasystoles were noted (over 12 beats per peak hour). There was a significant increase in the incidence of supraventricular extrasystoles at follow up compared with the preoperative sample group ${ }^{16}(p=0.003)$.

At follow up, isolated ventricular extrasystoles (Lown grade I) were seen in $37 \%$ $(23 / 62)$ of patients. However, in all but five of these there were fewer than five ventricular extrasystoles per trace. Two patients $(5 \%)$ with simple transposition had Lown grade II ventricular arrhythmia, while only one patient (2\%) showed infrequent multifocal ventricular extrasystoles (Lown grade III) on a follow up Holter recording. Lown grade IV and V ventricular arrhythmias were not seen. However, in the immediate postoperative period, one patient with simple transposition developed asymptomatic intermittent junctional tachycardia as well as intermittent ventricular tachycardia. He was briefly treated with oral amiodarone; a subsequent Holter recording showed sinus rhythm.

There was no correlation between arrhythmia and residual haemodynamic lesions. There was also no correlation with the coronary artery patterns. Two patients who had the infundibular branch sacrificed at surgery had normal Holter recordings and electrocardiograms at follow up, apart from a partial right bundle branch block. Another who required reimplantation of the right coronary artery also had a normal electrocardiogram and Holter recording on follow up. The second patient with right coronary transfer problems, however, developed infrequent multifocal ventricular extrasystoles on Holter recording, with partial right bundle branch block.

\section{Discussion}

A variable incidence of important cardiac arrhythmias has been reported after the Mustard and the Senning operations with the risk of late death associated with arrhythmia. ${ }^{24}$ Holter studies on patients after such surgery suggested an incidence of $30-70 \%$ of important cardiac arrhythmias. ${ }^{24-32}$ Junctional rhythm was the commonest abnormality noted. Several mechanisms have been proposed to explain this high incidence of arrhythmia. Initial reports prompted the suggestion that the high incidence of arrhythmia was inherent in transposition of the great vessels..$^{24}$ This assumption, however, has not been substantiated. Moreover, modifications of the Mustard and the Senning procedures have substantially reduced the incidence of arrhythmia. In addition preoperative Holter studies on patients with transposition of the great vessels, ${ }^{141628}$ including our sample group, have shown an incidence of arrhythmias similar to that seen in normal healthy infants and children, ${ }^{18-23}$ though one of our patients developed supraventricular tachycardia soon after balloon atrial septostomy.

Previous studies reporting arrhythmias after the arterial switch operation have included diverse groups of patients who had either a primary arterial switch or arterial switch after initial pulmonary artery banding. They also included patients who had ventriculotomies for closure of a ventricular septal defect at various ages. ${ }^{14-16}$ Nevertheless, arrhythmia was uncommon after operation and its frequency was not increased when surgery was carried out as a two stage procedure (after initial pulmonary artery banding) or when closure of a ventricular septal defect required a ventriculotomy. ${ }^{16}$ The only patients in whom complete heart block developed had had closure of a Blalock-Hanlon septectomy. ${ }^{1416}$ 
In this homogenous group of 73 neonates who had arterial switches we confirmed that postoperative conduction and rhythm disturbances were not common, even after closure of a ventricular septal defect. Only one infant developed a supraventricular tachycardia, which was well controlled by digoxin; an asymptomatic complete heart block developed in a second patient; and an intermittent Wenckebach block in a third. Martin et al also noted an increased incidence of supraventricular extrasystoles. ${ }^{16}$ This low incidence of important arrhythmias may reflect the safety of the procedure in skilled hands and the early age (most by two weeks) at which the correction was carried out: this latter factor was also suggested by others. ${ }^{16}$ The Mustard and Senning inflow diversions that are generally done in older infants and children are more likely to damage the sinus node or its blood supply, ${ }^{27}$ to interrupt "specialised" atrial conduction tissue or the atrioventricular node, and thus to contribute to sudden death. ${ }^{14}$

Partial and complete right bundle branch block have been reported after anatomical correction, even in patients with an intact ventricular septum..$^{15}$ The occurrence of complete right bundle branch block after operation in two $(4 \%)$ of our patients with simple transposition was unexplained. Both lacked evidence of myocardial ischaemia and had uncomplicated postoperative courses. None of our patients developed evidence of myocardial infarction or persistent ishaemia on the electrocardiogram or Holter trace at the last follow up (mean 27 months). There was no correlation between arrhythmia and residual haemodynamic lesions or between arrhythmia and coronary artery patterns. The two patients who had an infundibular branch sacrificed at surgery and a patient with right coronary artery transfer problems were in sinus rhythm and had partial right bundle branch block. Partial right bundle branch block is a normal finding in about $7 \%$ of children over the age of six months. A second patient with right coronary artery transfer problems developed infrequent multifocal ventricular extrasystyoles (Lown grade III) on follow up Holter monitoring.

Though some dispute that the risk of death associated with late arrhythmia is increased after atrial inflow diversion procedures ${ }^{31}$ the higher incidence of important arrhythmias after such surgery has been well documented. Our study confirms earlier reports of a low incidence of such arrhythmias after neonatal anatomical correction and the lack of persistent ischaemic changes in the short and medium term follow up. These findings indicate that neonatal correction has additional advantages over the Mustard and Senning procedures.

This study presented in part to the 3rd World Congress of Pediatric Cardiology, Bangkok, November 1989.

1 Williams WG, Freedom RM, Culham G, et al. Early experience with arterial repair of transposition. Ann Thorac Surg 1981;32:8-15.

2 Stark J. Transposition of the great arteries: Which operation? Ann Thorac Surg 1984;38:429-31.

3 Oldham HN Jr. Arterial repair of transposition. Ann Thora Surg 1981;32:1-3.

4 Flemming WH. Why switch? J Thorac Cardiovasc Surg 1979;78:1-2.
5 Zannine L, Lecompte Y, Jarreau MM, Hazan E. Transposition of the great arteries with ventricular septal defect: analysis of a series of 30 patients. Pediatr Cardiol 1983;4(suppl I):109-14.

6 Yacoub MH, Bernhard A, Radley-Smith R, et al. Supravalvarpulmonary uenosis after anatomic correction of transposition of the great arteries: causes and prevention. Circulation 1982;66(suppl 1 ); $193-7$

7 Brawn WJ, Mee RBB. Early results of antet correction of transposition of the great arteries and for double outlet right ventricle with subpulmonary ventricular septa defect. $J$ Thorac Cardiovasc Surg 1988;95:230-8.

8 Okuda $M$, Nakazawa $M$, Imai $Y$, et al. Comparison of ventricular function after Senning and Jatene procedures for transposition of the great arteries. $A m J$ Cardiol 1985;55:530-4.

9 Sievers HH, Lange PE, Onnasch DG, et al. Influence of two stage anatomic correction of simple transposition of the great arteries on left ventricular function. Am J Cardiol 1985;56:514-9.

10 Borow KM, Arensman FW, Webb C, Radley Smith R, Yacoub MH. Assessment of left ventricular contractile Yacoub MH. Assessment of left ventricular contractile state after anatomic correction of tran

11 Vogel M, Benson LN, Smallhorn JF, et al. Catheter assessment of left ventricular function after arterial switch operation at rest and afterload stress [abstract]. $J \mathrm{Am} \mathrm{Col}$ Cardiol 1988;11:29A.

2 Sandor GS, Freedom RM, Williams WG, et al. Left ventricular systolic and diastolic function after two stage anatomic correction of transposition of the great arteries. Am Heart J 1988;115:1257-62.

13 Arensman FW, Radley-Smith R, Yacoub MH, et al. Catheter evaluation of left ventricular shape and function one or more years after anatomic correction of transposition of the great arteries. Am J Cardiol 1983;52:1079-83.

14 Arensman FW, Bostock J, Radley-Smith R, Yacoub MH. Cardiac rhythm and conduction before and after anatomic correction of transposition of the great arteries. $\mathrm{Am}$ Cardiol 1983;52:836-9.

15 Lange PE, Pulse W, Sievers HH, et al. Cardiac rhythm and conduction after two-stage anatomic correction of simple transposition of the great arteries. Thorac Cardiovasc Surg 1986;34:22-4.

16 Martin RP, Radley-Smith R, Yacoub MH. Arrhythmias before and after anatomic correction of transposition of the gefore and after anatomic correction of transposit

17 Gillette PC, Garson A, eds. Texas Children's Hospital electrographic criteria: normal values in pediatric cardiac dysrhythmias. New York: Grune and Stratton, 1981: 452-3.

18 Southall DP, Richards J, Mitchell P, Brown DJ, Johnston PGB, Shinebourne EA. Study of cardiac rhythm in healthy newborn infants. Br Heart J 1980;43:14-20.

19 Southall DP, Orrell MJ, Talbot JF, et al. Study of cardiac arrhythmias and other forms of conduction abnormality in newborn infants. $B M J$ 1977;ii:597-9.

20 Southall DP, Johnston F, Shinebourne EA, Johnston PGB 24-hour electrocardiographic study of heart rate and rhythm patterns in population of healthy children. $B r$ Heart $J$ 1981;45:281-91.

21 Montague TJ, Taylor PG, Stockton R, Roy DL, Smith ER The spectrum of cardiac rate and rhythm in normal newborns. Pediatr Cardiol 1982;2:33-8.

22 Nagashima M, Matsushima M, Ogawa A, et al. Cardiac arrhythmias in healthy children revealed by 24 hour ambulatory ECG monitoring. Pediatr Cardiol 1987;8:103-8.

23 Valimaki I. Tape recordings of the electrocardiograms in newborn infants, Section II. Long term ECG tape recordings of newborn in

24 Southall DP, Keeton BR, Leanage R, et al. Cardiac rhythm and conduction before and after Mustard's operation fo complete transposition of the great arteries. Br Heart 1980;43:21-30.

25 Clarkson PM, Barratt-Boyes BM, Neutze JM. Late dysrhythmias and disturbances of conduction following Mustards operation for complete transposition of the great arteries. Circulation 1976;53:519-24.

26 Saalouke MG, Rios J, Perry LW, Shapiro SR, Scott LP. Electrophysiologic studies after Mustard's operation for d-transposition of the great vessels. Am J Cardio 1978;41:1104-9.

27 Gillette PC, Kugler JD, Garson A Jr, et al. Mechanisms of cardiac arrhythmias after the Mustard operation for transposition of the great arteries. $\mathrm{Am} \mathrm{J}$ Cardiol 1980;45:1225-30.

28 Martin TC, Smith L, Hernandez A, Weldon CS. Dysrhythmias following the Senning operation for transposition of the great arteries. J Thorac Cardiovasc Surg 1983;85: the great

29 Beerman LB, Neches WH, Fricker FH, et al. Arrhythmias in transposition of the great arteries after the Mustard transposition of the great arteries aft

30 Flinn CJ, Wolff GS, Dick M, et al. Cardiac rhythm after Mustard's operation for complete transposition of the Mustard's operation for complete transposit
great arteries. $N$ Engl J Med 1984;310:1635-8.

great arteries. N Engl Med 1984;310:1635-8. late mortality after Mustard and Senning operation for late mortality after Mustard and Senning operation for
transposition of the great arteries. An eight-year prospectransposition of the great arteries. An eight-year prospec-

32 Williams WG, Trusler GA, Kirklin JW, et al. Early and late results of a protocol for simple transposition leading to an results of a protocol for simple transposition leading to an
atrial switch (Mustard) repair. J Thorac Cardiovasc Surg atrial switch (M 